archives

of thermodynamics

Vol. 36(2015), No. 2, 61-74

DOI: $10.1515 /$ aoter-2015-0015

\title{
Comparison of results of experimental research with numerical calculations of a model one-sided seal
}

\section{DAMIAN JOACHIMIAK ${ }^{1}$ \\ PIOTR KRZYŚLAK}

Poznan University of technology, Chair of Thermal Engineering, Piotrowo 3, 60-965 Poznań, Poland

\begin{abstract}
Paper presents the results of experimental and numerical research of a model segment of a labyrinth seal for a different wear level. The analysis covers the extent of leakage and distribution of static pressure in the seal chambers and the planes upstream and downstream of the segment. The measurement data have been compared with the results of numerical calculations obtained using commercial software. Based on the flow conditions occurring in the area subjected to calculations, the size of the mesh defined by parameter $y^{+}$has been analyzed and the selection of the turbulence model has been described. The numerical calculations were based on the measurable thermodynamic parameters in the seal segments of steam turbines. The work contains a comparison of the mass flow and distribution of static pressure in the seal chambers obtained during the measurement and calculated numerically in a model segment of the seal of different level of wear.
\end{abstract}

Keywords: Labyrinth seals; Turbomachines; Fluid-flow machines

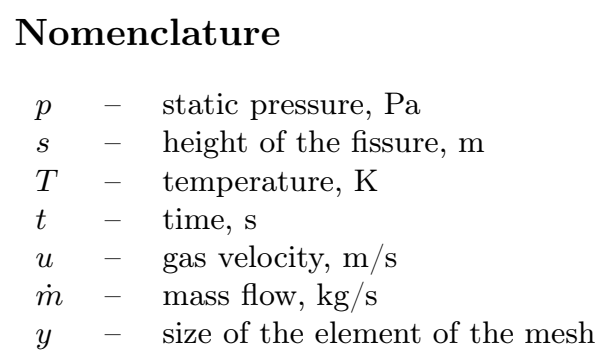

\footnotetext{
${ }^{1}$ Corresponding Author. E-mail: damian.joachimiak@put.poznan.pl
} 


\section{Greek symbols}

$$
\begin{array}{lll}
\mu & - & \text { dynamic viscosity, } \mathrm{Pa} \mathrm{s} \\
\nu & - & \text { kinematic viscosity, } \mathrm{m}^{2} / \mathrm{s} \\
\rho & - & \text { density, } \mathrm{kg} / \mathrm{m}^{3}
\end{array}
$$

\section{Subscripts}

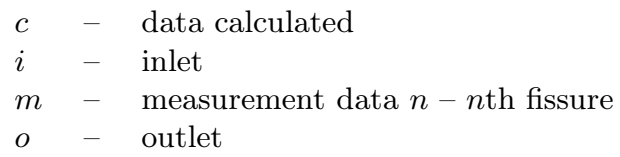

\section{Introduction}

It is impossible to perform a direct measurement of the steam mass flow leaking through the segments of a labyrinth seal in an operating steam turbine. However, estimation of the leakage level is possible based on the measurement of the static pressure and temperature in the segment of the stuffing box $[9,14]$. The analysis of static pressure in a one-sided seal with spiral discs has been described in [11]. The work contains a comparison of results of experimental research and computational fluid dynamics (CFD) calculations for a seal composed of a single disc of a helix geometry fitted in the casing. CFD calculations were performed using commercial Fluent software, based on the $k$ - $\varepsilon$ turbulence model and the Reynolds stress model.

Numerical calculations of a double-sided seal of perpendicular discs inclined towards the surface of the shaft are given in [13]. The paper contains a comparison of the distribution of static and dynamic pressures, Mach number and the velocities along the seal.

A comparison of the flow coefficients, velocity and pressure distribution in a one-sided seal containing several discs can be found in $[15,12]$. Paper [12] contains a detailed analysis of the influence of the geometry of the one sided seal blades on the flow coefficient taking into account the coefficient of kinetic energy transfer. Paper [4] contains a comparison of the mass flow obtained in the measurements with selected one dimensional calculation models for a one-sided seal of different level of wear. From the analysis, it results that the majority of known models can only be applied to a certain level of wear. One-sided seals have a small range of geometry wear for which the actual leak is smaller than the theoretical. Hence, one-dimensional theoretical models do not allow determining the value of the mass flow for one-sided seals of high level of wear.

The investigations presented in the paper were conducted in the aspect 
of methodology of seal diagnostics. The data for the calculations are the thermodynamic parameters that can be measured on an operating steam turbine. Commercial sofware Ansys-CFX [17] served to determine the leakage and static pressure occurring in the model segment of the seal.

In the diagnostic method [9] the basic information on the current condition of the geometry of the stuffing box segment is the change of the static pressure in the seal resulting from its wear and a disturbance of the flow generated by the bleed. The paper contains an introduction to the research on the diagnostic methods utilizing CFD. The presented results of experimental research and numerical calculations pertain to the seal without flow disturbance. The results presented in the paper will lead to an evaluation of the efficiency of calculations based on the CFD methods for one sided seal. The values of the mass flow and static pressure distribution have been compared in the model segment of the seal. The conclusion from the research provides information whether it is possible to calculate the leakage and reproduce the line of pressure distribution with the CFD methods for a one-sided seal.

\section{Object of the research}

The analysis of the measurement data and numerical calculations presented in the paper is related to the axisymmetric geometry of the segment of a onesided seal.

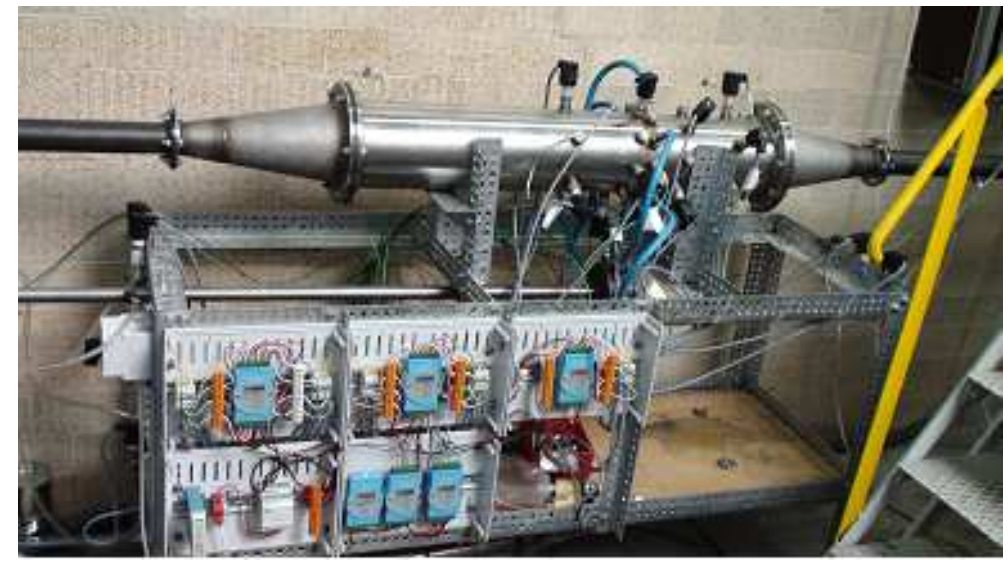

Figure 1: The test stand. 
The test stand was powered with compressed air. The analysis was performed on a segment of a one-sided seal containing 20 discs placed centrically in the casing. The discs were fixed on the shaft of the model seal [2]. Individual geometrical gauges have been shown in Tab. 1.

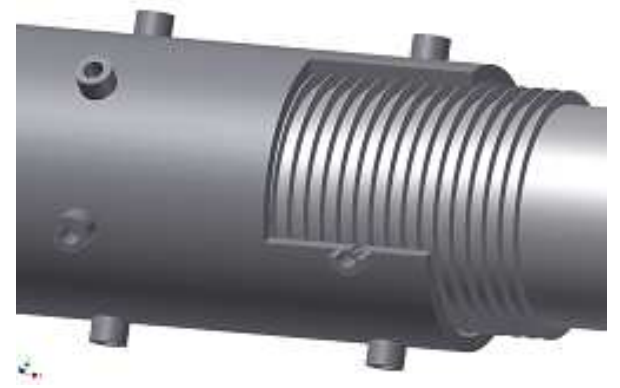

Figure 2: Geometry of the seal.

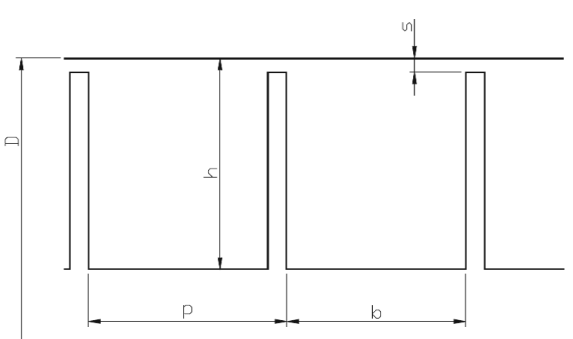

Figure 3: Cross-section of the seal with the description of the symbols.

Table 1: Parameters of the investigated geometries.

\begin{tabular}{|l|c|l|}
\hline Name & Symbol & \multicolumn{1}{|c|}{ Size } \\
\hline \hline Diameter & $\mathrm{D}$ & $0.150[\mathrm{~m}]$ \\
\hline Calibration & $\mathrm{p}$ & $0.01[\mathrm{~m}]$ \\
\hline Height of the fissure & $\mathrm{s}$ & $0.0003 ; 0.0005 ; 0.0007 ;$ \\
& & $0.001 ; 0.0015 ; 0.002[\mathrm{~m}]$ \\
\hline Length of the chamber & $\mathrm{b}$ & $0.009[\mathrm{~m}]$ \\
\hline Height of the seal & $\mathrm{h}$ & $0.01[\mathrm{~m}]$ \\
\hline Number of seals & $\mathrm{n}$ & $20[-]$ \\
\hline
\end{tabular}

The test stand allows for a measurement of the mass flow on the orifices placed in the inlet and outlet channels. The measurement data have been processed in software of own design calculating and balancing the mass flows in individual orifices of the test stand. The outstanding data obtained during the investigations were pressures upstream and downstream of the seal and distribution of static pressure in the seal chambers. 

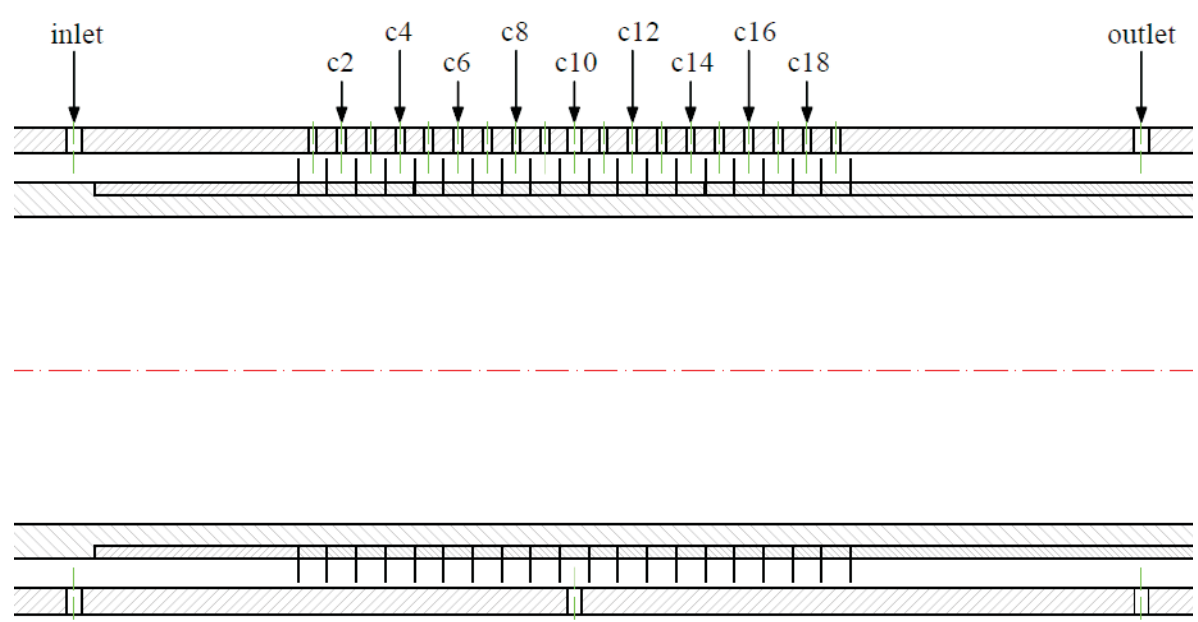

Figure 4: Distribution of the measurement points of static pressure and temperature in the main planes inlet, outlet and seal chambers $\mathrm{c} 2, \mathrm{c} 4, \ldots, \mathrm{c} 18$.

\section{Assumptions of the numerical calculations}

\subsection{Geometry}

In the tested seal segment, the flow of gas was axisymmetric. The numerical calculations allowed for the fragment of geometry of the thickness $g=0.1 \mathrm{~mm}$. The size of the mesh was estimated based on the flow parameters occurring in the calculated area. Areas of high velocity, acceleration or pressure change gradients require a mesh of the smallest size. The size of the mesh was estimated for the parameters occurring in the last fissure in the segment where the gas velocities are the highest. Based on the mass flow calculated from the measured data allowing for the seal geometry, the average velocity and Reynolds number in the last fissure of the segment were determined and identified as follows:

$$
\operatorname{Re}=\frac{u s}{\nu},
$$

where $u$ is the gas velocity, $s$ is the fissure hight, and $\nu$ is the kinematic viscosity. Based on the assumed Reynolds number, the size of the element of the mesh in the fissure was analyzed. The size of the mesh for the flow parameters is expressed in the Reynolds number as a function of dimensionless 
parameter $\mathrm{y}^{+}[17]$

$$
y=s y^{+} \sqrt{80} \operatorname{Re}^{-13 / 14},
$$

where $y^{+}$is the distance between the first node and the surface of the wall was determined. With parameter $y^{+}$, the distance between the first node and the surface of the wall was determined. The required size of mesh $y$ in the area of the 20th narrowing for the tested geometries has been given in Tab. 2, where additionaly values of $c_{n=20}$ and $\operatorname{Re}_{n=20}$ are given, which denote the velocity and Reynolds number in the last fissure of the segment, respectively.

Table 2: Size of mesh $y$ depending on the assumed parameter $y^{+}$calculated based on the measurement data.

\begin{tabular}{|l||l|l|l|l|l|l|}
\hline $\mathrm{s}$ & 0.0003 & 0.0005 & 0.0007 & 0.001 & 0.0015 & 0.002 \\
\hline$c_{n=20}$ & 126 & 133 & 131 & 126 & 94 & 82 \\
\hline $\mathrm{Re}_{n=20}$ & 2499 & 4428 & 6472 & 9824 & 11626 & 11138 \\
\hline$y^{+}$ & \multicolumn{7}{|c|}{$\mathrm{y}[\mathrm{m}]$} \\
\hline 2 & 0.000004 & 0.000004 & 0.000004 & 0.000004 & 0.000004 & 0.000004 \\
\hline 10 & 0.000019 & 0.000019 & 0.000019 & 0.000019 & 0.000019 & 0.000019 \\
\hline 100 & 0.000191 & 0.000191 & 0.000191 & 0.000191 & 0.000191 & 0.000191 \\
\hline
\end{tabular}

The values of parameter $y^{+}$close to 1 allows performing accurate numerical calculations. For the construction of the mesh, three-dimensional tetragonal elements were used. The discretization of the flow channel was done in commercial CFX Mesh [17]. Near the narrowings of the stuffing box, where great changes of velocity and pressures were expected, the density of the mesh was increased (Fig. 5). The increased density covered areas between the narrowings in the upper part of the chambers where the occurrence of airflow of high velocity was predicted.

The size of the mesh was selected depending on the height of the fissures and measurement data (Tab. 2) in order to have at least five layers in the fissure. The maximum thickness of the wall layer was determined as $1 / 5$ of the height of fissure, $s$. The number of elements of the generated meshes for individual geometries has been given in Tab. 3 .

Table 3 contains average and maximum values of parameter $y^{+}$occurring on the surface of the casing and the shaft. The average values of this parameter were calculated against individual areas. The maximum values of $y^{+}$occurring on both surfaces provide information on the quality of the 


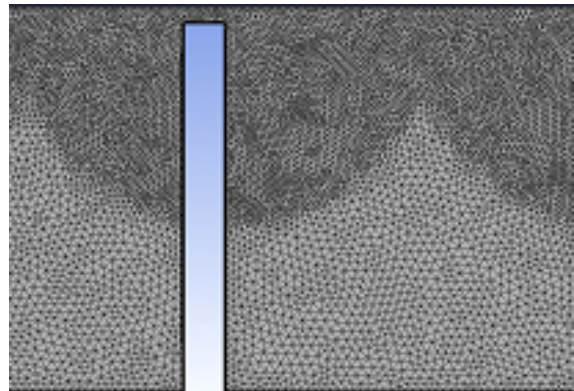

a)

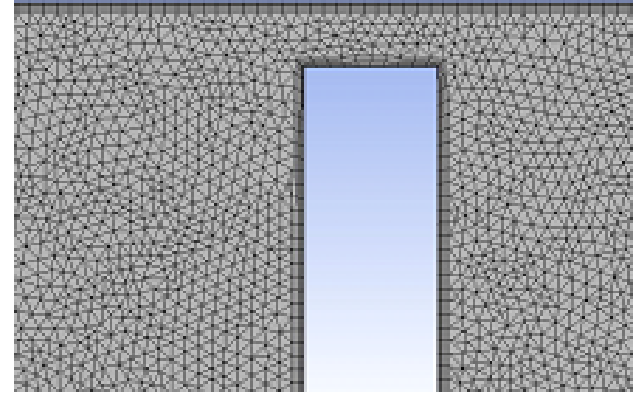

b)

Figure 5: Mesh of increased density: a) of the upper part of the chamber, between the fissures, b) wall layer.

Table 3: The number of elements of the mesh and the number of nodes for the tested geometries. Average and maximum values of parameter $y^{+}$occurring on the surface of the casing and the shaft.

\begin{tabular}{|l||c|c|c|c|c|c|}
\hline $\mathrm{s}$ & 0.0003 & 0.0005 & 0.0007 & 0.001 & 0.0015 & 0.002 \\
\hline number of elements & 1351255 & 884106 & 522880 & 237898 & 616771 & 664809 \\
\hline number of nodes & 407503 & 323369 & 196416 & 593995 & 243817 & 272705 \\
\hline$y^{+}$casing average & 2.0 & 2.2 & 2.4 & 2.5 & 3.1 & 1.3 \\
\hline$y^{+}$shaft average & 1.1 & 2.2 & 1.2 & 1.1 & 1.4 & 0.6 \\
\hline$y^{+}$casing MAX & 2.9 & 5.8 & 3.0 & 3.0 & 4.0 & 1.7 \\
\hline$y^{+}$shaft MAX & 2.6 & 4.8 & 3.1 & 2.6 & 3.3 & 1.4 \\
\hline
\end{tabular}

mesh at the spot where the flow parameters are most varied and require the highest mesh density.

\subsection{Boundary conditions}

In the inlet plane to the area under calculation, the static pressure and the temperature of air were set as ambient with a regular direction of the velocity to this plane of low turbulence. In the outlet plane, the average static pressure was the value measured. The correctness and convergence of the numerical calculations was verified through the set boundary conditions. The assumed static pressure downstream and upstream of the seal conditions the resultant pressure distribution in the seal for which in the calculated area the equation of continuity, energy and momentum are pre- 
served with the assumed model of turbulence. Dissipation of kinetic energy was allowed in stationary calculations. Termination of iterative calculations, aside from reaching sufficiently low values of root mean square (RMS) of selected parameters, is triggered by attaining the assumed accuracy of the mass flow in the inlet and outlet planes.

\subsection{Model of turbulence}

Commercial software Ansys-CFX [17], used for the numerical calculations, has many built-in models of turbulence. These include the RANS models of Reynolds stress models that can be divided into two groups: models based on the hypothesis of turbulent viscosity and models of Reynolds stress. For the calculations, the SSG model was used based on the equations of transport for six components of the tensor of turbulent stress and dissipation of kinetic energy. Since this model takes into account the anisotropy of the Reynolds stress tensor, it should better suit the simulation of more complex flows $[10,17]$. In the Reynolds stress models the executive module solves the equations of Reynolds stress transport whose notation can be as follows [17]:

$$
\begin{aligned}
\frac{\partial \rho \bar{u}_{i} \bar{u}_{j}}{\partial t}+\frac{\partial}{\partial x_{k}}\left(U_{k} \rho \bar{u}_{i} \bar{u}_{j}\right)-\frac{\partial}{\partial x_{k}} & {\left[\left(\mu+\frac{2}{3} C_{s} \rho \frac{k^{2}}{\varepsilon}\right) \frac{\partial \bar{u}_{i} \bar{u}_{j}}{\partial x_{k}}\right]=} \\
& =P_{i j}-\frac{2}{3} \delta_{i j} \rho \varepsilon+\phi_{i j}+P_{i j, b}
\end{aligned}
$$

where $\varphi_{i j}$ is the pressure-strain correlation, $\varepsilon$ and $k$ denote dissipation of kinetic energy, and the kinetic energy of turbulence, respectively, $\delta_{i j}$ is the Kronecker delta, $P_{i j b}$ is the production due to buoyancy, and overbar $(\cdot)$ denotes the velocity averaged over time, $P_{i j}$ is the exact production term, responsible for the production of kinetic energy of turbulence determined with the formula

$$
P_{i j}=-\rho\left(\bar{u}_{i} \bar{u}_{k} \frac{\partial U_{j}}{\partial x_{k}}+\bar{u}_{j} \bar{u}_{k} \frac{\partial U_{i}}{\partial x_{k}}\right) .
$$

It is a very significant component in the Reynolds stress models. In the SSG model pressure-strain correlation, $\phi_{i j}$, takes a square form, hence the model can be more accurate than the SST, LRR-IP or LRR-Qi models in which the pressure-strain correlation is linear $[10,17]$. 


\section{Character of the flow of gas in the seal}

The air under high pressure gradually decompresses while flowing through the subsequent fissures. The tracing of these values is presented by the step line (Fig. 6). In each subsequent fissure, the gas accelerates to higher speeds. In the seal chamber, dissipation of kinetic energy into heat energy of gas takes place. The flow of gas in the seal is characterized with a high level of turbulence.

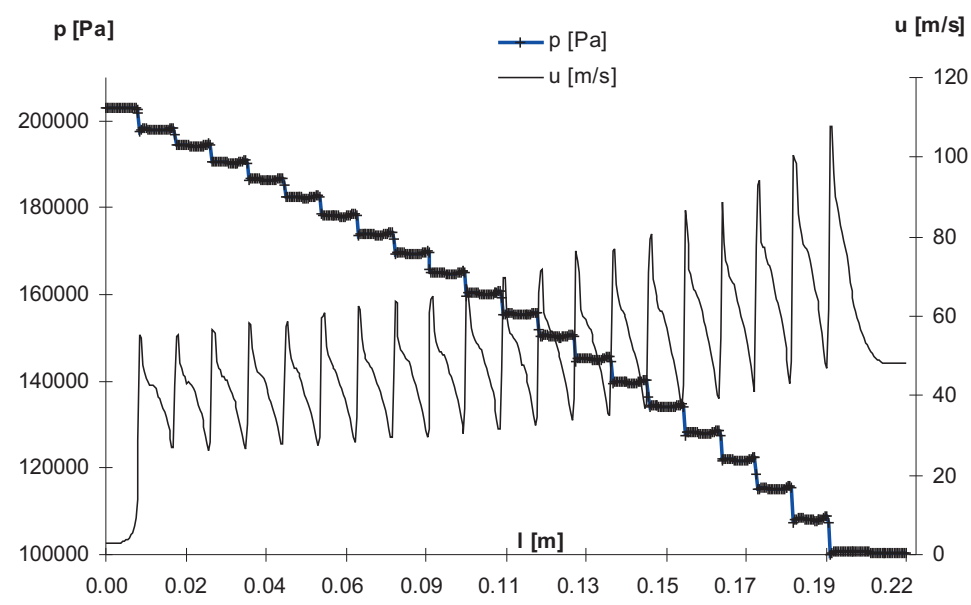

Figure 6: Static pressure and axial velocity along the seal on the line at half height of the fissures pulled from numerical calculations.

The static pressure measured in the seal chambers on the test stand correspond to the pressure in the central part of the horizontal portions of the step line (Fig. 6).

\section{Comparison of numerical calculations and experimental data}

In order to verify the correctness of numerical calculations the obtained mass flows and static pressures were compared with the experimental results. The obtained results have been shown in Tab. 5 and in Fig. 7 .

For the description of the pressure distribution in the seal, parameter $p_{n}$ was used which is defined as the ratio of the pressure difference between 
a given point $n, p_{N}$, and the pressure downstream of the seal, $p_{o}$, to the drop of pressure on the entire length of the seal

$$
p_{n}=\frac{p_{N}-p_{o}}{p_{i}-p_{o}},
$$

where $p_{i}$ and $p_{o}$ are the inlet and outlet pressure, respectively. The numerical calculations for individual geometries were performed for the thermodynamic values given in Tab. 4. The length of the seal was described with parameter: $n=N / 20$, where $\mathrm{N}=0,1, \ldots, 20$.

The validation of the performed numerical calculations is a comparison of the mass flows measured on the test stand with those obtained in the numerical calculations (Tab. 5).

Table 4: Initial pressure and temperature and the final pressure obtained during the measurements and set within the boundary conditions for the numerical calculations.

\begin{tabular}{|l||c|c|c|c|c|c|}
\hline $\mathrm{s}[\mathrm{m}]$ & 0.0003 & 0.0005 & 0.0007 & 0.001 & 0.0015 & 0.002 \\
\hline$p_{i}[\mathrm{~Pa}]$ & 203050 & 212750 & 214050 & 200700 & 177100 & 130680 \\
\hline$p_{o}[\mathrm{~Pa}]$ & 100949 & 104900 & 214050 & 123300 & 131550 & 105150 \\
\hline$T_{i}[\mathrm{~K}]$ & 296.95 & 295.95 & 297.45 & 297.45 & 298.75 & 296.75 \\
\hline
\end{tabular}

Table 5: Mass flows obtained in the measurements and in the numerical calculations.

\begin{tabular}{|l||l|l|l|l|l|l|}
\hline $\mathrm{s}$ & 0.0003 & 0.0005 & 0.0007 & 0.001 & 0.0015 & 0.002 \\
\hline$\dot{m}_{m}[\mathrm{~kg} / \mathrm{s}]$ & 0.01439 & 0.03305 & 0.05263 & 0.08745 & 0.1010 & 0.09625 \\
\hline$\dot{m}_{c}[\mathrm{~kg} / \mathrm{s}]$ & 0.01752 & 0.03695 & 0.04271 & 0.06122 & 0.08211 & 0.09599 \\
\hline$\dot{m}_{c} / \dot{m}_{m}[-]$ & 1.11 & 0.94 & 1.2 & 0.935 & 0.813 & 0.997 \\
\hline
\end{tabular}

The level of wear was determined with the height of fissure, $s$. The distribution of the pressure obtained during the measurement for the nominal height of the fissure (Fig. 7a) and that bearing small traces of wear (Fig. 7b and c) have the tracings that form a convex line. In segments of increasing wear (Fig. $7 \mathrm{c}-\mathrm{e}$ ), the lines of pressure distribution are getting flatter. For a worn seal (Fig. 7e), the measured pressure distribution is linear and for the extremely worn seal (Fig. 7f), the line of pressure distribution is concave. For graphs (Fig. 7d-f), an increasing drop of pressure in the first fissure is 
observed. This phenomenon was observed earlier by Zimmerman and Wolff who described the results of experimental research and calculations for a three-fissure segment of a seal under operation [16].

The greatest similarity of the pressure distribution in the numerical calculations and measurement data was obtained for segments $s=0.0003$ and $0.0005 \mathrm{~m}$. For these geometries, the static pressure distribution is almost identical with the measurement data. The mass flow error amounts to $11 \%$ and $6 \%$. Segment $s=0.0007$ had largest mass flow error of the values of $20 \%$. Segments $0.001,0.0015$, and $0.002 \mathrm{~m}$ had smaller mass flow error of the values of $6.5,18.7$, and $3 \%$. Yet, for these geometries, the obtained pressure distribution significantly deviates from the measured values.

\section{Conclusions}

In the numerical calculations, the boundary conditions were static pressures in the inlet and outlet planes. A lack of kinetic energy in these planes may result in a divergence in the iterative calculations. Hence, the initial iterations of the calculations were done with a small scale of the order of $10^{-6} \mathrm{~s}$. Such a small time-scale also resulted from the complexity of the flow in the model segment of the stuffing box.

Calculated static pressure profile is convergent with the measurement data only for nominal geometry and that of little wear (Fig. 7a,b). For worn segments (Fig. 7c,d,e,f), these values significantly deviate from the experimental data.

The analysis presented in the paper aimed at comparing the mass flow and static pressure distribution obtained during the measurements with the results of numerical calculations performed on the basis of minimum assumed static pressures in the inlet and outlet planes.

Comparing the mass flows measured and calculated indicates that when the kinetic energy is taken into account, it is possible to obtain results that are more accurate.

Divergences of the mass flows measured and those calculated on the measured side may result from the test stand workmanship accuracy tolerance, i.e., the channels, where the orifices are placed, the orifices themselves, seal geometry (inner diameter of the casing, outer diameter of the discs of the seal segment). On the side of the numerical calculations, the differences may result from the assumed geometry. It was built based on the averaged inner diameter of the casing and the outer diameter of the sets of discs in- 
a)
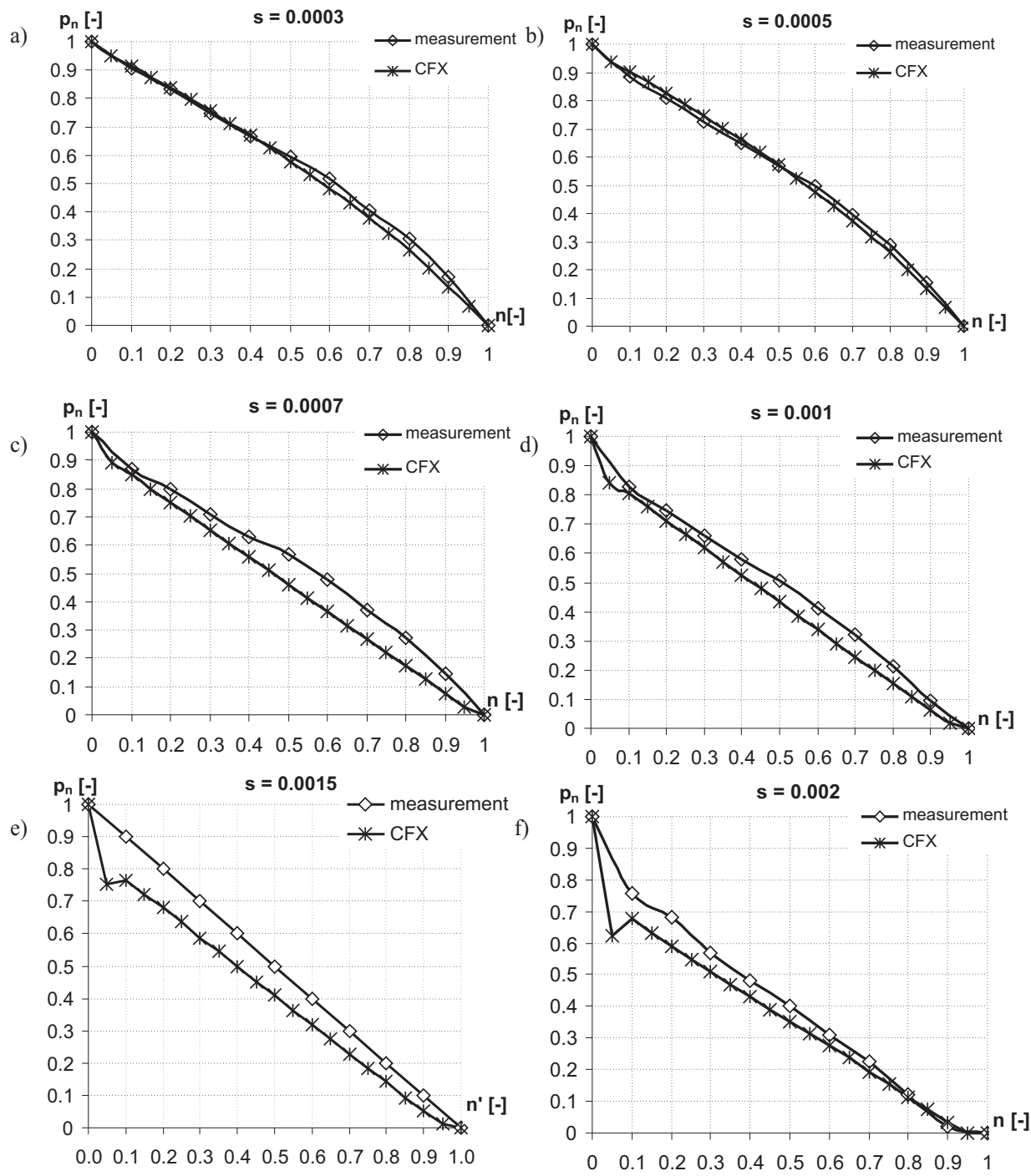

Figure 7: Dimensionless value of static pressure along the seal obtained during the measurements and from numerical calculations.

cluded in the measurements.

The subject of the calculations was a geometry consisting of 20 fissures. The averaging of the height of the fissures of such geometry may result in divergences of the mass flow. Aside from the geometry, the precision of the 
measurement of the mass flow is influenced by the accuracy of the pressure converters in the measurement orifices.

Acknowledgements The tests were performed on a test stand designed and built as part of the grant number 3247/B/T02/2011/40.

Received 8 March 2013

\section{References}

[1] Gamal Eldin A.M.: Leakage and rotordynamic effects of pocket damper seals and see-through labyrinth seals. $\mathrm{PhD}$ thesis, Texas A\&M University, 2007.

[2] Joachimiak D.: The labyrinth seals research with extraction. PhD thesis, Poznan University of Technology, Poznan 2013 (in Polish).

[3] Joachimiak D., Joachimiak M., Krzyślak P.: The analysis of the calculation process related to labyrinth sealing with extraction. Int. J. Appl. Mech. Eng. 18(2013), 4, 1057-1067.

[4] Joachimiak D., Krzyślak P.: Comparison of the calculation methods labyrinth seals and determination flow factor on the basis of experimental data. In: Machinery and Equipment Power (S. Łopata, Ed.) Proc. 3rd Tech. Sci. Conf., Cracow 2013, 105-114 (in Polish).

[5] JoAchimiak D., KRzYŚlak P.: Calculation of labyrinth seals with extraction. Int. J. Appl. Mech. Eng. 16(2011), 1, 5-14.

[6] Johchimiak D., Joachimiak M., Krzyślak P.: Description program Dławnica used for calculations labyrinth seals. J. Mech. Transport Eng. 65(2013), 1, 25-35 (in Polish).

[7] Joachimiak D., Krzyślak P.: Comparsion of one dimensional carculations models for compresible and incompresible flow by labirynth seals. J. Mech. Transport Eng. 64(2011), 51-67 (in Polish).

[8] KRzYŚlAK P., Winowiecki M.: A method of diagnosing labyrinth seals in fluidflow machines. Pol. Marit. Res. 15(2008), 3(57), 38-41.

[9] Krzyślak P., Winowiecki M.: RP Patent Office: P-379431 - acknowledgement of patent submission. Flow seal in a fluid-flow machine and method of its diagnostics. Warsaw 2006 (in Polish).

[10] Kuczkowski M.: Numerical simulation of a turbulent flow through the strongly curved duct witch different RANS turbulence model. Turbomachinery 131(2007), $51-60$.

[11] Morrison G., Al-Ghasem A.: Experimental and computational analysis of a gas compressor windback seal. Proc. Asme Turbo Expo 2007, Vol. 4, Pt. B, 1231-1247.

[12] Tipton D. L., Scott T. E., Vogel T. E.: Analytical and experimental development of a design model for labyrinth seals. Air force wright aeronautical laboratories, Allison Gas Turbine-Division of General Motors Corporation, 1985. 
[13] Vakili D., Meganathan A.: An Experimental and Numerical Study of Labyrinth Seal Flow. Proc. Asme Turbo Expo 2005, Vol. 3, Pt. B, 1121-1128.

[14] Winowiecki M.: The method of diagnosing labyrinth seals on machines. PhD thesis, Poznan University of Technology, Poznań 2009 (in Polish).

[15] Wittig S., Schelling, U., Kim, S., Jacobsen, K.: Numerical predictions and measurements of discharge coefficients in labyrinth seals. ASME Gas Turbine Conference, Anaheim, California 1987, 1-7.

[16] Zimmerman H., WolfF K.H.: Comparison between empirical and numerical labyrinth flow correlations. ASME Gas Turbine Conference, Anaheim, California 1987, 1-6.

[17] ANSYS Academic Research, Release 14, Help System. ANSYS, Inc. 